\title{
Deep Femoral Vein
}

National Cancer Institute

\section{Source}

National Cancer Institute. Deep Femoral Vein. NCI Thesaurus. Code C154776.

A vein located in the upper thigh that connects, through tributaries, to the popliteal and inferior gluteal veins, and joins the superficial femoral vein at the groin to form the common femoral vein. 